\title{
Editorial: Reduction, Emergence, and Physics
}

Received: 17 March 2011 / Accepted: 4 May 2011 / Published online: 15 May 2011

(C) Springer Science+Business Media, LLC 2011

How do the theories of physics relate to each other? Is there one truly fundamental theory to which all other theories reduce? Or are our best physical theories only loosely related, with no clear hierarchical ordering amongst them? Addressing these questions requires a combination of philosophical analysis and a detailed study of specific physical theories and models. The philosophical analysis clarifies concepts such as reduction, emergence and supervenience and asks, for example, whether reduction and emergence are compatible with each other. The case-studies, on the other hand, relate these analyses to physics, they inspire them and test them. Undertaking this task was the aim of the workshop "Reduction, Emergence, and Physics" that took place at the Tilburg Center for Logic and Philosophy of Science on April 9, 2008. The workshop paid special attention to case-studies from statistical mechanics and quantum theory and assembled a number of physicists and philosophers of physics to engage in a lively debate. The present Special Issue grew out of this workshop. It contains revised versions of some of the papers presented at the workshop as well as several new ones. We would like to thank the editor of this journal, Professor Gerard 't Hooft, for inviting us to guest-edit this Special Issue, and all authors and referees for their excellent work.

Stephan Hartmann and Giovanni Valente 